\title{
The 34th International Conference on Solution Chemistry Special Issue
}

\author{
W. Earle Waghorne ${ }^{1}$
}

Published online: 19 October 2016

(C) Springer Science+Business Media New York 2016

This is the second issue of the Journal of Solution Chemistry devoted to papers presented at the International Conference on Solution Chemistry. The previous issue was based on papers from the 33rd ICSC, held in Kyoto Japan in 2013 and the present one on papers from the 34th ICSC held in Prague, Czech Republic, in 2015.

The ICSC meetings are held biennially and provide a forum for chemists working across the whole range of solution chemistry, as can be seen from the selection of papers in the current issue, which include papers dealing with chemistry in natural waters, defluoridation of waste waters, simulations of hydronium species in non-aqueous solutions, the effect of salts on nonionic surfactant systems and nuclear reprocessing among many others. ${ }^{1}$

The ICSC meetings always provide an enjoyable venue for solution chemists to renew old friendships and make new ones and the beautiful city of Prague provided the perfect backdrop.

The ICSCs are truly international meetings ${ }^{2}$ with recent meetings being held in Perth (Australia), Innsbruck (Austria), La Grande Motte (France) and Kyoto (Japan). The 35th ICSC is scheduled for Richmond, Virginia (USA) June 4-8, 2017.

\footnotetext{
1 As an IUPAC sponsored conference the invited lectures from the ICSC are published in Pure and Applied Chemistry (see the March issue of PAC).

2 International Steering Committee: I. Persson (Sweden), Chair; Ariel A. Chialvo (United States); Glenn Hefter (Australia); Alenka Luzar (United States); Jalel Mhalla (Tunisia); Ivo Nezbeda (Czech Republic); Pál Sipos (Hungary); Toshio Yamaguchi (Japan).
}

W. Earle Waghorne

solution.chemistry3@gmail.com

1 UCD School of Chemistry, University College Dublin, Dublin, Ireland 